\title{
Absorbing Aerosols and Summer Monsoon Evolution over South Asia: An Observational Portrayal
}

\author{
Massimo Bollasina AND Sumant Nigam \\ Department of Atmospheric and Oceanic Science, Earth System Science Interdisciplinary Center, University of Maryland, \\ College Park, College Park, Maryland \\ K.-M. LAU \\ Laboratory for Atmospheres, NASA Goddard Space Flight Center, Greenbelt, Maryland
}

(Manuscript received 12 June 2007, in final form 11 December 2007)

\begin{abstract}
The South Asian haze builds up from December to May, is mostly of anthropogenic origin, and absorbs part of the solar radiation. The influence of interannual variations of absorbing aerosols over the IndoGangetic Plain in May on the Indian summer monsoon is characterized by means of an observational analysis. Insight into how the aerosol impact is generated is also provided.

It is shown that anomalous aerosol loading in late spring leads to remarkable and large-scale variations in the monsoon evolution. Excessive aerosols in May lead to reduced cloud amount and precipitation, increased surface shortwave radiation, and land surface warming. The June (and July) monsoon anomaly associated with excessive May aerosols is of opposite sign over much of the subcontinent (although with a different pattern) with respect to May. The monsoon strengthens in June (and July).

The analysis suggests that the significant large-scale aerosol influence on monsoon circulation and hydroclimate is mediated by the heating of the land surface, pursuant to reduced cloudiness and precipitation in May. The finding of the significant role of the land surface in the realization of the aerosol impact is somewhat novel.
\end{abstract}

\section{Introduction}

The aerosol influence on the earth's radiation budget is better understood now than it was a few years ago, but it still remains the dominant uncertainty in climate change scenarios (IPCC 2007; Anderson et al. 2003). Several factors make identifying and quantifying aerosol effects on climate challenging (e.g., Menon 2004), and a substantial amount of literature on various aerosol effects now exists (see Menon 2004 for a review). Anthropogenic activities have been implicated in raising the aerosol concentration in the troposphere (e.g., Massie et al. 2004; Sarkar et al. 2006). Over polluted regions, the aerosol forcing at the surface and in the atmosphere can be an order of magnitude larger than

Corresponding author address: Massimo Bollasina, Department of Atmospheric and Oceanic Science, University of Maryland, College Park, 3417 Computer and Space Science Building, College Park, MD 20742-2425.

E-mail: massimo@atmos.umd.edu those of anthropogenic greenhouse gases, as is the case for the Indo-Asian haze (Ramanathan et al. 2005).

One of the areas of the world with higher aerosol concentration is South Asia, a result of recent rapid urbanization and population growth. The Indian Ocean Experiment (INDOEX) (Ramanathan et al. 2001) revealed that a 3-km-thick brownish haze layer, composed of anthropogenic [up to $75 \%$ of the average aerosol optical depth (AOD)] (Lelieveld et al. 2001) and natural aerosols, is spread over most of the tropical Indian Ocean toward the Himalayan region (Ramana et al. 2004) and extends over Southeast Asia into the western Pacific (e.g., Rajeev et al. 2000). INDOEX documented the persistence of the brown cloud for several months from winter to spring, its large black carbon (BC) content (up to $10 \%-14 \%$ of the total aerosol mass), and the large perturbation to the radiative energy budget of the region (up to $-25 \mathrm{~W} \mathrm{~m}^{-2}$ in the mean clear-sky radiation at the surface). During the last few years, observational studies have further characterized the aerosol composition and properties (e.g., Eck 
et al. 2001; Hsu et al. 2003; Ramanathan and Ramana 2005; Gautam et al. 2007).

In the same period, atmospheric and coupled oceanatmosphere models have been used with quasi-realistic aerosol distributions to clarify the aerosol-monsoon linkage. The contribution of absorbing aerosols to the long-term changes of rainfall over India was investigated by Chung et al. (2002), Menon et al. (2002), Ramanathan et al. (2005), Lau et al. (2006), Chung and Ramanathan (2006), and recently by Meehl et al. (2008). Chung et al. (2002) used an atmospheric model with sea surface temperatures (SSTs) fixed to their climatological cycle and aerosol forcing imposed in terms of a radiative forcing perturbation (from October to May) over the Indian Ocean, derived from INDOEX measurements. The results (limited to winter and spring months) showed that the aerosols induced surface cooling by reducing solar radiation at the surface but also produced a warming of the lower troposphere by absorption. The dynamical response was large: from the enhancement of the meridional temperature gradient in the atmosphere and increased low-level convergence, which in turn led to stronger premonsoon rainfall. Menon et al. (2002) investigated the effects of absorbing aerosols on the summer monsoon using a similar modeling strategy, that is, a climate model with specified SSTs. The modeling analysis showed precipitation to decrease over the north equatorial Indian Ocean and northern China and to increase over southern China and portions of India. The authors attributed this variation to the heating of the air and its effects on temperature profile, convection strength, and induced large-scale ascending motion. Lau et al. (2006) have also ascertained the effects of absorbing aerosols on the summer monsoon with an atmospheric model forced by specified SSTs and proposed an "elevated heat pump" hypothesis: anomalous accumulation of absorbing aerosols (transported dust from the nearby deserts and BC from regional sources) against the southern slopes of the Himalayas induces a large-scale upper-level heating anomaly over the Tibetan Plateau in April and May that reinforces the meridional temperature gradient and intensifies the monsoon over India in June and July.

However, the impact of aerosols on monsoon rainfall in a coupled model was found to be different from that in uncoupled models with specified SSTs (Chung et al. 2002; Menon et al. 2002; Lau et al. 2006) as a result of the response of SSTs themselves to aerosol forcing. Ramanathan et al. (2005), using a coupled ocean-atmosphere model with aerosols over South Asia prescribed according to measurements, found that, while aerosol absorption of solar radiation and consequent heating of the atmosphere leads to enhanced upward motion over India during winter, it also leads to a weakening of the monsoon circulation and a reduction of rainfall over India during summer. The latter effect was attributed to the aerosol-induced decrease of the meridional SST gradient in the Indian Ocean, with a consequent cooler trend of SSTs in the northern Indian Ocean than in the southern part. Chung and Ramanathan (2006) sought to estimate the two influences by running an atmospheric model with specified SSTs, imposing separately the SST trend in the Indian Ocean and the South Asian haze radiative forcing. Large-scale circulation changes arising from the modulation of the meridional SST gradient (simulating an interactive ocean) more than offset the rainfall increment resulting from increased ascending motions induced by aerosol heating of the low troposphere (keeping SSTs fixed), with an overall decrease of monsoon rainfall over India. Recently, Meehl et al. (2008) also used a coupled climate model, but with a time-evolving global distribution of $\mathrm{BC}$ aerosols (with all the other natural and anthropogenic forcings fixed to their preindustrial values), to investigate the effects on the Indian monsoon. A present-day distribution of $\mathrm{BC}$ was generated by assimilating satellite retrievals of optical depths and using a chemistry-transport model. They found that BC aerosols lead to an increase of premonsoon rainfall over India but to a decrease in the monsoon season, with season-averaged break monsoon conditions associated with cooler SSTs in the Arabian Sea and the Bay of Bengal and warmer SSTs to the south (i.e., a weaker latitudinal SST gradient), confirming the findings of Ramanathan et al. (2005).

The aforementioned studies describe the potential effects of aerosols on monsoon rainfall over the Indian Subcontinent, but with heavy reliance on models. The problem is challenging given the complexity of the radiative, cloud-microphysics, and hydrometeorological processes involved and their interaction with the largescale circulation. Climate system models are a valuable tool for clarification of the underlying mechanisms; however, some caution is necessary as these models are known to have significant, and in many cases unacceptable, biases in quantities as basic and relevant as the monsoon rainfall distribution and onset (e.g., Annamalai et al. 2006). The biases often reflect inadequacies of the model physics in representing the ocean-atmosphere/ ocean-land interactions in play during the monsoon.

Aerosol-monsoon interaction was recently studied using observations by Lau and Kim (2006, hereafter LK06), who found support for their elevated heat pump hypothesis primarily from the analysis of precipitation and atmospheric circulation datasets. 
The present study is complementary to most earlier ones because it focuses on the interannual variability of aerosol concentration and related monsoon rainfall variation and because it is observationally rooted. The long-term aerosol trend is, in fact, removed from the record prior to analysis. An observational portrayal of aerosol-monsoon interactions is derived from rigorous analysis of remotely sensed datasets and atmospheric reanalysis. Although similar in some respects to LK06, the focus here is on the variations over the vast IndoGangetic Plain (IGP) and the distinction in the response over the eastern and western regions as opposed to the whole Indian sector in LK06. Another difference with respect to LK06 is the focus on land surface in this paper, whose state, including contrast with adjoining bays and oceans, is fundamental to monsoon onset and evolution. The land surface focus, however, is not one of choice but is dictated by the comprehensive analysis of aerosol-induced monsoon transitions between late spring and early summer when aerosol concentration reaches a peak (in the annual and interannual variations). Examination of diabatic heating, outgoing longwave radiation, temperature and moisture profiles, surface air temperature, surface radiative and heat fluxes, and cloudiness distributions not only complements the customary analysis of monsoon hydroclimate, but is essential in building a compelling picture of the aerosolmonsoon interactions.

Our results suggest that, although anomalously high aerosols are associated with deficient precipitation over India in early spring, internal atmosphere-land surface feedback actually strengthens the monsoon in subsequent summer months. Land surface processes, once triggered by anomalous aerosol concentration, are important mediators in monsoon evolution.

This paper is organized as follows: section 2 presents the data used in the analysis. Section 3 describes the variability of absorbing aerosols over India. Section 4 shows the large-scale pattern of the aerosol-induced anomalies in atmospheric circulation and the land surface state, and discusses a possible mechanism for the link. Discussion and conclusions follow in section 5.

\section{Data and analysis}

The distribution and variability of the aerosols is described in terms of the aerosol index (AI) derived from the Total Ozone Mapping Spectrometer (TOMS) measured radiances (Herman et al. 1997). The TOMS instrument has been operating aboard a series of satellites from 1978 to 2005 . The AI is defined so that positive values correspond to UV-absorbing aerosols and negative values correspond to nonabsorbing aerosols (Torres et al. 2002). A temporal gap of three years exists between 1993 and 1996, mainly because the data from the Meteor-3 satellite were not used in aerosol data processing owing to its precessing orbit (Herman et al. 1997).

The TOMS project has produced the longest available global record of aerosol observations in terms of $\mathrm{AI}$, and a number of studies have demonstrated its feasibility and success (e.g., Torres et al. 1998; Chiappello et al. 1999; Hsu et al. 1999; Cakmur et al. 2001; Prospero et al. 2002; Duncan et al. 2003). Monthly data on a $1.25^{\circ} \times 1^{\circ}$ grid are available on the TOMS Web site (http://toms.gsfc.nasa.gov/aerosols/aerosols_v8.html).

A preliminary comparison of Nimbus-7 (1978-93) and Earth Probe (1996-2005) AI data over the Indian Subcontinent and available documentation [e.g., Kiss et al. (2007); http://toms.gsfc.nasa.gov/news/news.html] revealed significant differences in terms of the mean annual cycle and time series of the area-averaged AI. A calibration drift was reported in 2000, instrumental problems were also noticed in 2001, and a warning to use caution in trend analysis with data after 2000 was also released in 2001 (see http://toms.gsfc.nasa.gov/ news/news.html). Because of these problems, the study focused only on the period 1979-92.

Atmospheric and surface variables are derived from the 40-yr European Centre for Medium-Range Weather Forecasts (ECMWF) Reanalysis (ERA-40) (Uppala et al. 2005) monthly data on a $2.5^{\circ} \times 2.5^{\circ}$ grid and at 23 vertical isobaric levels and were obtained from the National Center for Atmospheric Research (NCAR). ERA-40 was produced by running the spectral model at T159 (roughly $125 \mathrm{~km}$ ) horizontal resolution (and with 60 vertical hybrid levels). The diabatic heating was diagnosed as a residual of the thermodynamic equation (Hoskins et al. 1989; Nigam 1994; Chan and Nigam 2008, manuscript submitted to J. Climate).

Monthly precipitation data came from the Global Precipitation Climatology Project (GPCP) version 2 (Adler et al. 2003), the Climate Prediction Center (CPC) Merged Analysis of Precipitation (CMAP) (Xie and Arkin 1997), and the Climatic Research Unit (CRU) TS 2.1 dataset (Mitchell and Jones 2005). Both GPCP and CMAP precipitation are available on a $2.5^{\circ} \times 2.5^{\circ}$ grid, while CRU precipitation is at $0.5^{\circ} \times$ $0.5^{\circ}$ over land only. In the following analysis, the observation-only CMAP product was used, which does not include precipitation values from the National Centers for Environmental Prediction (NCEP)-NCAR reanalysis. It is worth remembering that land stations used in CRU are quite sparse over India north of about $20^{\circ} \mathrm{N}$ and over surrounding regions (e.g., New et al. 2000).

Surface shortwave and longwave radiation data were obtained from the Global Energy and Water Cycle Ex- 
periment (GEWEX) Surface Radiation Budget (SRB) Project (Gupta et al. 1999; see http://grp.giss.nasa.gov/ gewexdsetsbrowse.html) and from the International Satellite Cloud Climatology Project (ISCCP) radiative flux dataset (FD) (Zhang et al. 2004). (Both datasets are available on a $2.5^{\circ} \times 2.5^{\circ}$ grid from January 1984 onward at http://isccp.giss.nasa.gov/products/browsed2.html.)

Outgoing longwave radiation (OLR) data was provided by the NOAA/Earth System Research Laboratory (Liebmann and Smith 1996) as monthly averages at $2.5^{\circ}$ horizontal resolution (see http://www.cdc.noaa. gov/cdc/data.interp_OLR.html). Despite some limitations, the OLR is commonly used as a proxy for deep convection and rainfall in most tropical regions.

ISCCP-D2 series (Rossow et al. 1996) monthly mean total and low/middle/high cloud amount data available from July 1983 on a $2.5^{\circ} \times 2.5^{\circ}$ grid were also used (see http://isccp.giss.nasa.gov/products/browsed2.html).

The analysis used a linearly detrended time series for all variables. Detrending the data minimizes the influence of trends on the strength and significance of the deduced correlations/regressions.

\section{TOMS aerosol index variability over the Indian Subcontinent}

Several studies have documented that aerosol concentration over the South Asian region progressively builds up during the dry season (October-April; e.g., Rajeev and Ramanathan 2002). The October-May distribution of the AI over the Indian Subcontinent reveals that the Indo-Gangetic plain is one of the areas with high loading of aerosols, the other areas being the Arabian Peninsula and the Taklamakan Desert. Observations show that the IGP experiences a very persistent and heavy aerosol burden (AOD > 0.4) with peak concentrations in May (e.g., Ramanathan and Ramana 2005) and composition in large part made up of absorbing aerosols (single-scattering albedo as low as 0.85 , Ramanathan et al. 2001).

This study is focused on the effects of accumulated absorbing aerosols on the summer monsoon transition from the premonsoon phase to the active regime. The aerosol loading will be represented by the May AI as widespread monsoon rainfall in June rapidly washes out the aerosols except over northwestern India. Figure 1 displays the AI distribution over a $14-y r$ period. The spatial average of the AI over the IGP, formally the area with May standard deviation greater than 0.48 , was used to monitor the interannual variability. Although the choice of the threshold seems somewhat arbitrary, the analysis is not too sensitive to different selections.

Figure 1a clearly shows that aerosols are pushed against the Himalayan range with a distinct maximum over the IGP. The area of highest loading is longitudinally extended toward northwestern India and Pakistan where a secondary maximum is present. The continuance of the westerly flow in spring across Afghanistan and Pakistan contributes to the piling up of aerosols in May. Indeed, during the premonsoon season, air masses carry the dry dust particles from the Middle East and the western Thar Desert (where dust activity peaks in late spring to early summer; see, e.g., Prospero et al. 2002) to the IGP where they accumulate and interact with the large flux of regional pollutants from fossil fuels (typically invariant through the season) and biomass burning (predominant in spring; e.g., Dey et al. 2004; Habib et al. 2006).

The Indo-Gangetic Plain is also the region of highest AI standard deviation, with variability amplitude equaling $\sim 30 \%$ of the mean (Fig. 1b). The standard deviation distribution shows a northwest to southeast structure, like the climatology. During this 14 -yr period, the AI exhibits a positive trend (between +0.02 and $+0.1 \mathrm{yr}^{-1}$ ) in the months from March to June over a wide area encompassing India, the Arabian Sea, and Saudi Arabia. In May the trend has a pronounced core over the IGP, with values greater than $0.1 \mathrm{yr}^{-1}$. Figure 1c displays the original time series of the AI for the IGP. The trend, explaining $34 \%$ of the variance, is 0.086 $\mathrm{yr}^{-1}$, which, using a two-tailed $t$ test, is significant at the 95\% confidence level. The aerosol variations exhibit considerable spatial coherence as seen from the May correlation structure of the IGP averaged AI (Fig. 1d). The variation footprint (e.g., defined by the region with correlations $>0.9$ ) extends over much of eastern India in Fig. 1d.

The aerosol index over the IGP rapidly increases from February to May (about 4 times the mean winter values) and then rapidly decreases in June and July following the onset of monsoon rains (Fig. 1e). A secondary peak is seen in October. The seasonal cycle in other regions can peak in different months: from March over northeastern India where rainfall starts in April to June over northwestern India where dust transport from the nearby deserts is unabated until the onset of monsoon in June.

The aerosol anomalies over the IGP during May have a strong relationship with antecedent aerosol anomalies over the same region, as seen in the lead autocorrelations displayed in Fig. 1f (for completeness, correlations with April aerosol concentration are also shown). At a confidence level above $90 \%$, the interannual variations of the aerosol burden in May are linked to variations during March (lead $=-2$ ), suggesting the strong persistence of aerosol anomalies of the same sign throughout the spring until the rainy season. With the 
(a) Mean

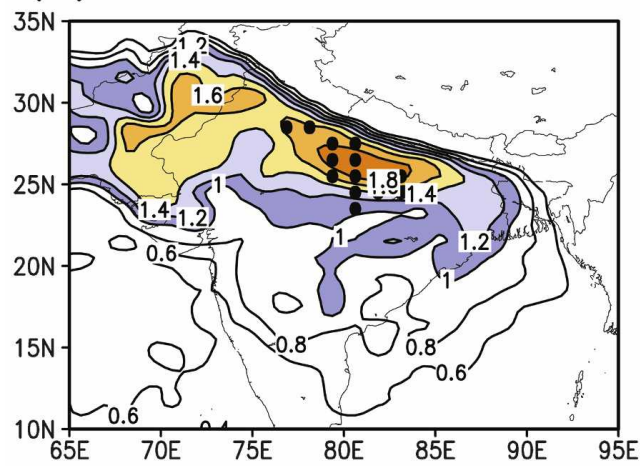

(c) Interannual Var.

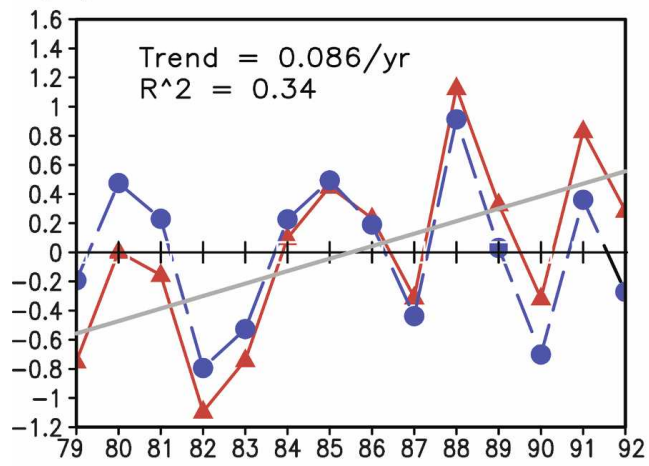

(e) Annual Cycle

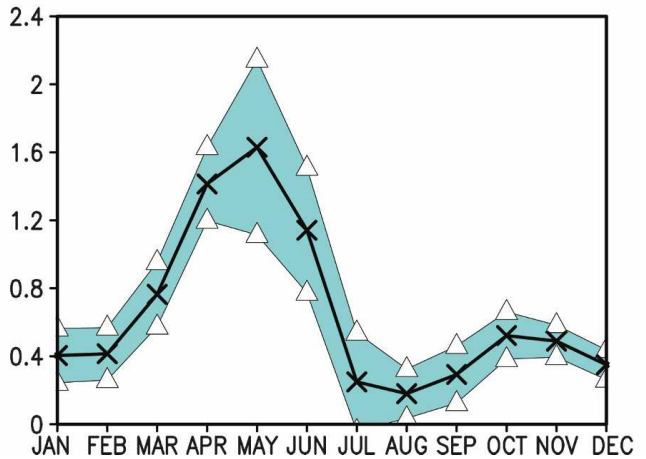

(b) Standard Dev.

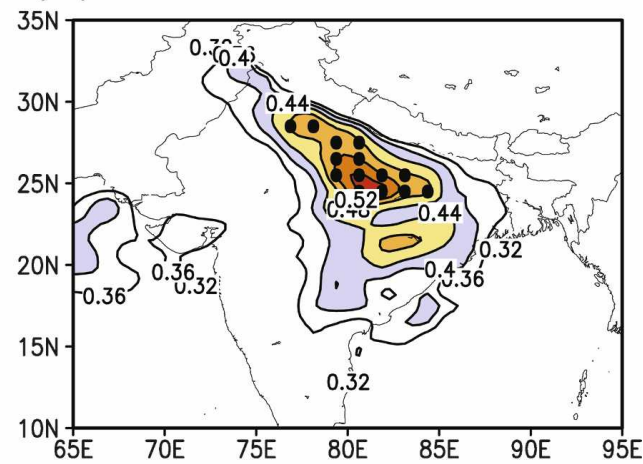

(d) Spatial Correlation

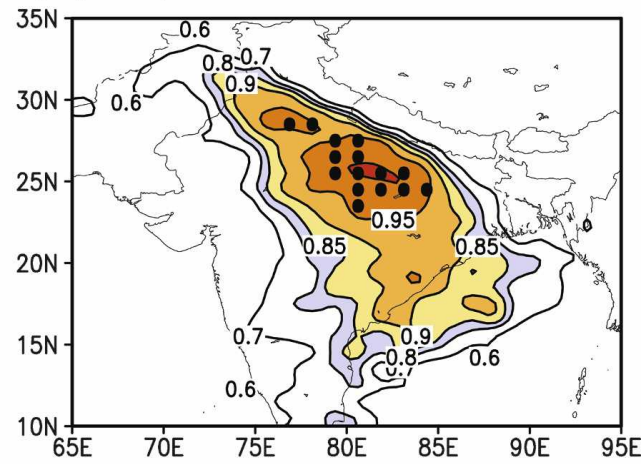

(f) Lead/Lag Autocorr.

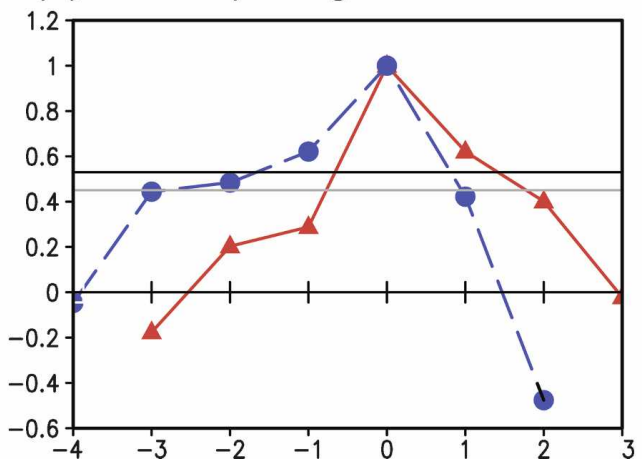

FIG. 1. Climatological (1979-92) characteristics of absorbing aerosols based on the TOMS AI (dimensionless) during May [except (e) and (f)]: (a) its distribution; (b) std dev; (c) time series of anomalies averaged over the region marked with black points in (a), (b), and (d) (solid line with triangles: original data; dashed line with closed circles: original data after removing trend; continuous straight line: least square fit); (d) spatial correlation of the detrended time series in (c); (e) annual cycle (crossed line) with the range of \pm 1 std dev around the mean enclosed by the shaded area; (f) lead/lag autocorrelations of April (solid line with triangles) and May (dashed line with closed circles) time series of AI anomalies averaged over the same region as in (c) and (e), with the $90 \%$ and $95 \%$ confidence levels as straight lines $(0.47$ and 0.53 , respectively). (f) The $x$ axis represents the month of lead/lag (if negative or positive, respectively) with respect to the base time (contemporaneous correlations). All data [except the continuous line in (c)] were displayed after removing the trend. The trend (d) is $0.086 \mathrm{yr}^{-1}$ with $R_{2}=0.34$. The black dots in (a), (b), and (d) show the points used in spatially averaging the AI and building the time series of anomalies, corresponding to locations with std dev $>0.48$. 

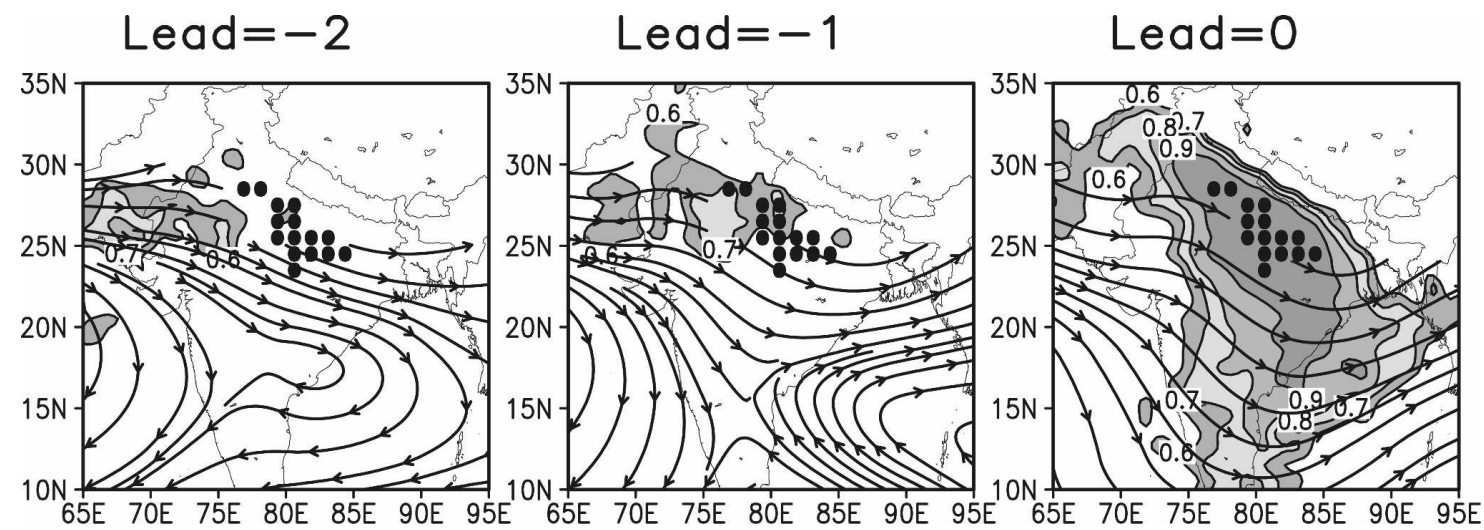

FIG. 2. Correlations (shaded) between the time series of May AI anomalies (see Fig. 1) and the AI distribution in March (lead: -2 , left), April (lead: -1; middle), and May (lead: 0, right; same as Fig. 1d), and the climatological (1979-92) horizontal wind at $850 \mathrm{hPa}$ represented as streamlines.

onset of the monsoon, the correlations sensibly drop, especially in July when rainfall is widespread over the IGP.

As mentioned earlier, dust from the deserts west of India is a large contributor to aerosol loading over the IGP. Indeed, Fig. 2 shows the spatial correlations of the aerosol anomalies over the IGP during May with the aerosol pattern during previous months (i.e., March and April) over the Indian Subcontinent. The climatological low-level westerly flow clearly carries the dust eastward, providing a constant source of aerosols over the IGP. In late spring, aerosols are then transported over eastern India and the Bay of Bengal, as seen from lagged correlations of the AI time series over the IGP (not shown).

In the following analysis, variability of the aerosols is represented by the detrended time series of May AI anomalies over the Indo-Gangetic Plain (i.e., the dashed line in Fig. 1c).

\section{Absorbing aerosols and South Asian summer monsoon evolution}

\section{a. AI and precipitation}

Figure 3 shows the regressed precipitation for May, June, and July. To corroborate the analysis, four different datasets are compared. During May, higher aerosol loading over the IGP is associated with lower precipitation over most of India, except the northeast. The negative precipitation anomaly is not directly centered over the IGP but shows a slight northwest to southeast orientation. The amounts are, on average, $0.5-1.5 \mathrm{~mm}$ day $^{-1}$, comparable to the 1979-92 climatological May precipitation (about $1-1.5 \mathrm{~mm} \mathrm{day}^{-1}$ ). Positive anomalies in the northeast are even greater than $3 \mathrm{~mm}^{-1 a y}{ }^{-1}$ but so is the climatology there $\left(5-10 \mathrm{~mm} \mathrm{day}^{-1}\right)$.

The situation is reversed in June: Associated with the anomalously high May AI is a positive precipitation anomaly over most of India (except the northwest) of magnitude greater than $1 \mathrm{~mm} \mathrm{day}^{-1}$, compared to the 3-5 mm day ${ }^{-1}$ June mean values. More abundant precipitation is also found over the ocean with intense regional maxima in the Bay of Bengal and off the Western Ghats in the Arabian Sea (about 4-7 mm day ${ }^{-1}$, compared to the $10-15 \mathrm{~mm}$ day $^{-1}$ mean values). High May AI is also accompanied by reduced precipitation in the north equatorial Indian Ocean.

The July regressions on May AI tend to be weaker and more diffuse, which is not unexpected, since aerosols can get washed out in the June rains. Even with weaker regressions, the datasets agree on the sign of the anomaly over India, southern slopes of the Himalayas, and over the southern Bay of Bengal.

That local maxima are in different areas through the season (i.e., deficient precipitation in May does not necessarily correspond to abundant precipitation in June/ July over the same region) is also noteworthy. Interestingly, June and July have anomalies of the same sign, positive over most of India.

The above analysis indicates that an initially anomalously large aerosol loading over the IGP at the end of the dry season potentially reduces the already modest premonsoon precipitation over India. ${ }^{1}$ However, as the season progresses, the anomaly changes sign and precipitation is actually increased in June and July; that is,

\footnotetext{
${ }^{1}$ Average (1979-92) monthly precipitation over India from the CRU dataset is $1.3 \mathrm{~mm} \mathrm{day}^{-1}$ in May, as opposed to larger values in the monsoon season: $4.4 \mathrm{~mm}$ day $^{-1}$ in June, $7.4 \mathrm{~mm}$ day $^{-1}$ in July, and $6.7 \mathrm{~mm}$ day $^{-1}$ in August.

${ }^{2}$ The August precipitation anomalies associated with high May aerosol loading are positive over northern India eastward of $80^{\circ} \mathrm{E}$ but negative over western, central, and southern India and over most of the Arabian Sea and the Bay of Bengal. Considering the Indian monsoon region as a whole, August precipitation is reduced.
} 

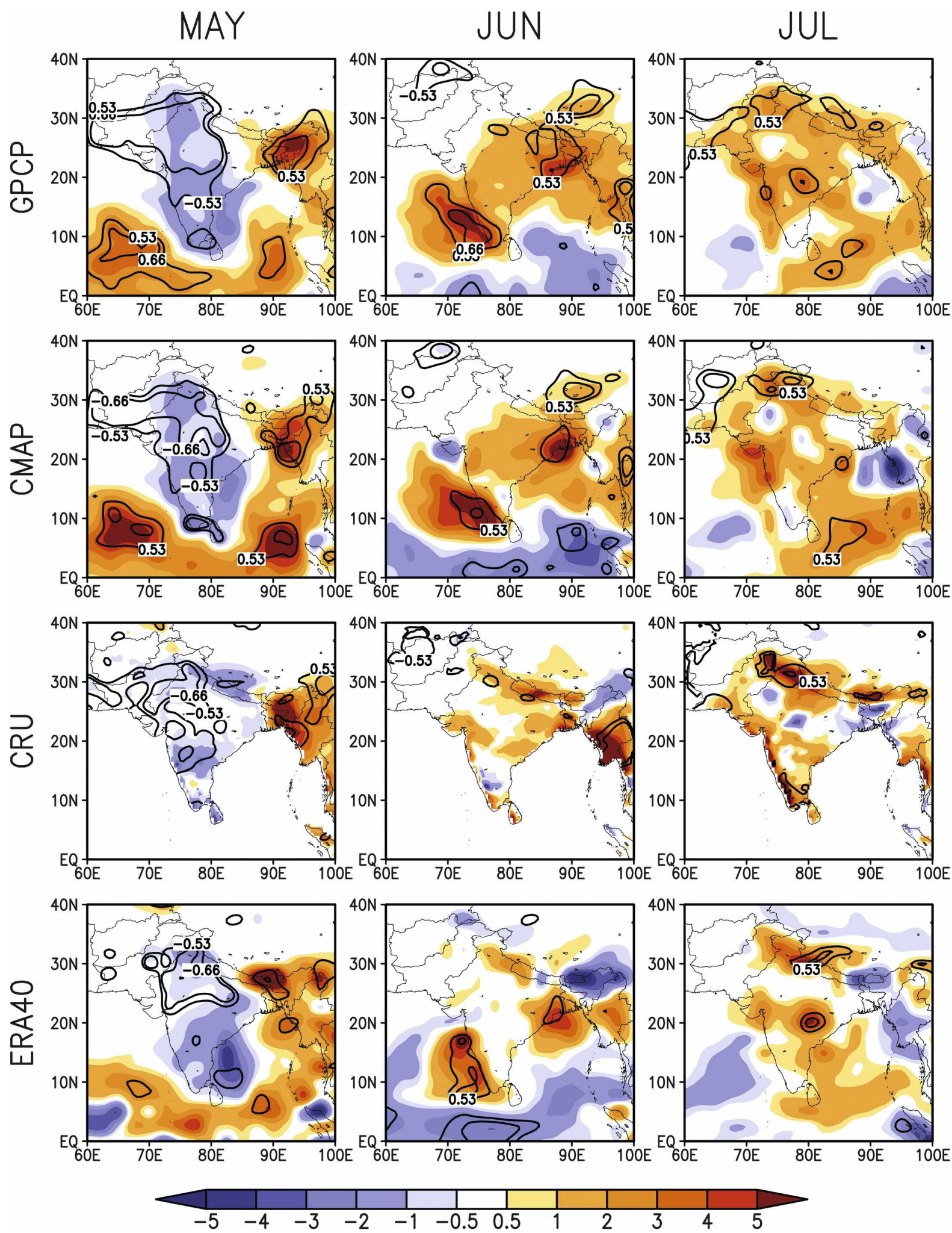

FIG. 3. Precipitation ( $\mathrm{mm} \mathrm{day}^{-1}$ ) regressed on the AI time series (see Fig. 1) for (left to right) May, June, and July based on (top to bottom) GPCP, CMAP, CRU, and ERA-40. The \pm 0.53 and \pm 0.66 contour lines show the $95 \%$ and $99 \%$ confidence levels, respectively. 

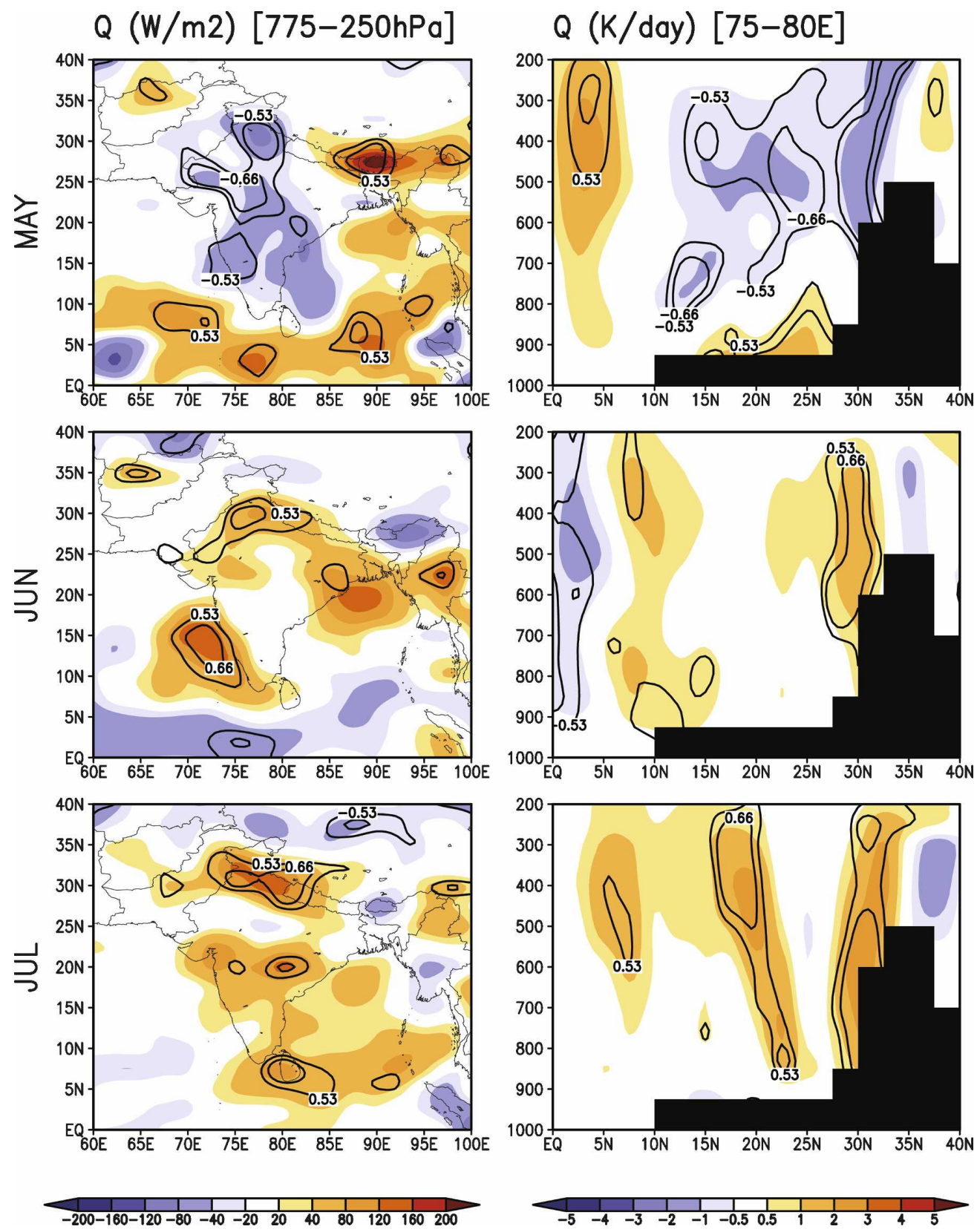

FIG. 4. Diabatic heating regressed on the AI time series (see Fig. 1) for (top to bottom) May, June, and July. (left) Monthly mean distribution of the mass-weighted vertical integral between 775 and $250 \mathrm{hPa}$ $\left(\mathrm{W} \mathrm{m}^{-2}\right.$ ). (right) Latitude-height cross section (average between $75^{\circ}-80^{\circ} \mathrm{E}$; values in $\mathrm{K}_{\text {day }}{ }^{-1}$ ), with topography in black. The \pm 0.53 and \pm 0.66 contour lines show the $95 \%$ and $99 \%$ confidence levels, respectively.

the monsoon becomes stronger, in agreement with LK06.

\section{b. AI and diabatic heating}

Diabatic heating regressed on the May AI time series is examined in Fig. 4 to gain insight into the origin of the AI-precipitation links. A display of partitioned heating components would be preferable, and more revealing, but these are not available on account of the residual diagnosis of heating. The three-dimensional heating structure (Fig. 4), however, can still be insightful, as seen shortly. Heating is, of course, very influen- 
tial on the large-scale circulation, especially in monsoon regions where the constituent latent heating is large and deep.

The left panels of Fig. 4 target this component, showing the midtropospheric heating. As expected, there is a close correspondence between vertically integrated diabatic heating and precipitation, especially for ERA-40 (last row in Fig. 3). During May, negative anomalies $\left(-30\right.$ to $\left.-60 \mathrm{~W} \mathrm{~m}^{-2}\right)$ are found over most of India, while a positive band extends from the Arabian Sea to the Bay of Bengal and over to northeastern India. Heating anomalies in June (and July) switch sign becoming positive over India, consistent with increased precipitation (cf. Fig. 3). The lower tropospheric ( $p>$ $775 \mathrm{hPa}$ ) heating anomalies are similar to the upper ones, except in May when there is a striking difference: positive anomalies $\left(5-20 \mathrm{~W} \mathrm{~m}^{-2}\right)$ over central and northern India (north of $\sim 15^{\circ} \mathrm{N}$; see the May vertical cross section in Fig. 3) with a core centered at $25^{\circ} \mathrm{N}$, $75^{\circ} \mathrm{E}$ are found underneath the negative midtropospheric heating anomalies. Note that, although the positive low-level heating anomalies are associated with larger aerosol burden, their core is not coincident with the maximum in aerosol distribution. Further analysis, in fact, suggests that these heating anomalies are related to variations in land surface heating (as seen later in Fig. 8).

The vertical structure of heating is displayed in the right columns of Fig. 4, the cross section being through the core region of reduced May precipitation. The opposite-signed anomalies in the lower and upper troposphere during May, mentioned earlier, are now evident, especially northward of $15^{\circ} \mathrm{N}$. Of particular interest are the positive anomalies extending from the surface up to $800 \mathrm{hPa}$ in the northern foothills region, with maximum heating rates $\left(\sim 1-2 \mathrm{~K} \mathrm{day}^{-1}\right)$ at the surface. Such surface-trapped vertical structure is characteristic of sensible heating, a point we return to later. In June, and later in July, precipitation moves northward and intensifies, but the northward progression is far from uniform as it rains over the Himalayan foothills first (in June) before it does over the Gangetic Plains and central India (in July). The heating anomaly over the southern slopes of the Himalayas is remarkable for its vertical reach to the tropopause. The core magnitude is about $+1.5 \mathrm{~K} \mathrm{day}^{-1}$ in June (at $500 \mathrm{hPa}$ ) and $+2.5 \mathrm{~K}$ day $^{-1}$ in July (at $600 \mathrm{hPa}$ ).

OLR regressions in Fig. 5 corroborate the midtropospheric heating analysis. OLR is a widely used indicator of deep convection in the tropics/subtropics with negative anomalies indicating deeper convection (e.g., Liebmann and Hartmann 1982). OLR is strongly positive over central and northwestern India in May, consistent with reduced precipitation and negative heating anomalies there (cf. Figs. 3, 4). The anomaly sign is reversed in June, as expected.

\section{c. AI and circulation}

Figure 6 shows in the left column the 1000-500-hPa integrated moisture flux (stationary + transient) anomaly and its convergence obtained, as before, from regressions on the May IGP AI time series. Southward (and divergent) moisture flux anomalies are seen over much of the Indian Subcontinent in May with fluxdivergence structure in accord with the precipitation and heating distributions (cf. Figs. 3 and 4). Another notable feature in the May plot is the eastward moisture transport from the Arabian Sea, which turns cyclonically and becomes northward over the Bay of Bengal, finally impinging on the eastern Himalayas $\left(\sim 90^{\circ} \mathrm{E}\right)$ and producing rain. In June, the eastward transport occurs in a more northerly belt where it encounters the Western Ghats, leading to upstream precipitation and a rain shadow over peninsular India.

The vertical structure of the circulation over central India is shown in the right column of Fig. 6. Low-level ascent and mid to upper level descent is in evidence in May, consistent with the dipolar heating structure (cf. Fig. 4) and the dominant thermodynamic balance in the tropics between diabatic heating and adiabatic cooling from vertical motion. ${ }^{3}$ Interestingly, this vertical motion field-low-level ascent and upper-level descentcan effectively trap and spread the aerosols at the top of the planetary boundary layer-vertical convergence $(-\partial \omega / \partial p)$ equals horizontal divergence $\left(\boldsymbol{\nabla} \cdot \mathbf{V}_{h}\right)$ from the continuity equation. Clearly there is scope for positive feedback here since increased and expansive aerosol loadings can generate stronger vertical motions from further precipitation (deep heating) reduction and surface heating.

Temperature and specific humidity profiles over central India linked with the IGP AI variations are shown in Fig. 7. Increased aerosol loading is associated with positive (negative) temperature (specific humidity) anomalies with maximum amplitude near the ground and a relative minimum in the midtroposphere in both cases. The lower troposphere anomalies are quite sig-

\footnotetext{
${ }^{3}$ This balance is generally in evidence well away from the surface (e.g., in the midtroposphere) — only there can vertical velocity be large enough for adiabatic cooling to offset diabatic heating. Nearer to the surface, horizontal thermal advection cannot be ignored even in the tropics. In fact, May streamlines suggest some offsetting of low-level heating by advection from the north. The thermodynamic balance is being quantitatively assessed from ERA-40 data.
} 


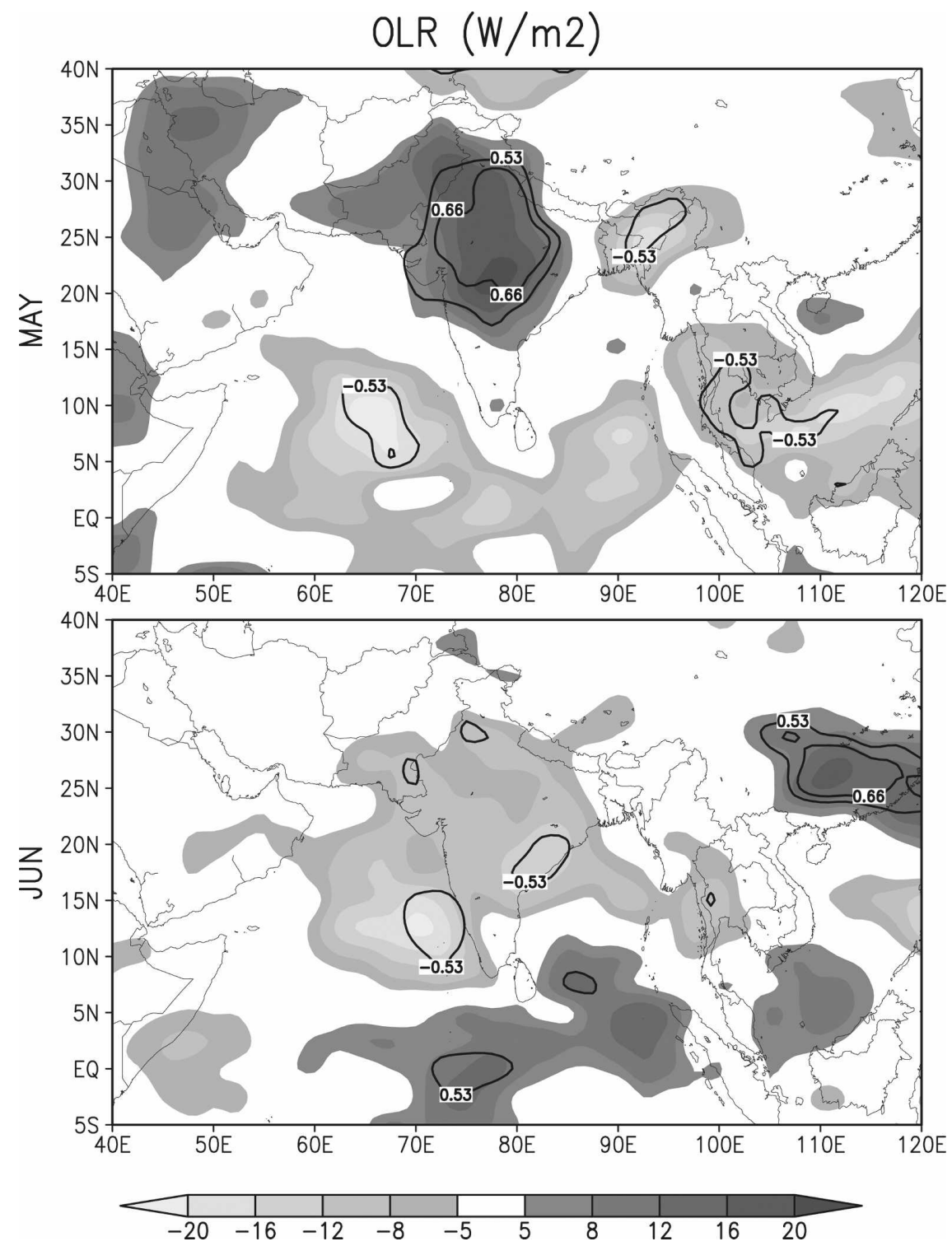

FIG. 5. OLR $\left(\mathrm{W} \mathrm{m}^{-2}\right)$ regressed on the AI time series (see Fig. 1) for (top) May and (bottom) June. The \pm 0.53 and \pm 0.66 contour lines show the $95 \%$ and $99 \%$ confidence levels, respectively.

nificant with correlation exceeding $0.8(0.5)$ for temperature (specific humidity). The vertical structure is entirely consistent with the presence of a heat source at the lower boundary, a heated land surface in this case, reflected also in the surface-trapped diabatic heating structure (cf. Fig. 4). A drier lower troposphere is also understood as resulting from a drier land surface since during the premonsoon period there is no other moisture source. The heating and drying of the land surface are, of course, related. The June (and July) profiles, on the other hand, are very different, reflecting a dramatic cooling and moistening of the lower troposphere stem- ming from enhanced precipitation (cf. Fig. 3) and resultant cooling and wetting of the underlying land surface.

\section{d. AI and surface heat and radiation fluxes}

The impact of AI variations on near-surface air temperature and sensible and latent heat flux is shown in Fig. 8. Immediately apparent is the strong positive anomaly in 2-m temperature over most of the subcontinent, with amplitude greater than $3 \mathrm{~K}$ in the core region $\left(30^{\circ} \mathrm{N}, 75^{\circ} \mathrm{E}\right)$. The temperature anomaly is broadly coincident with the region of reduced May pre- 
MF and Conv. [1000-500hPa]
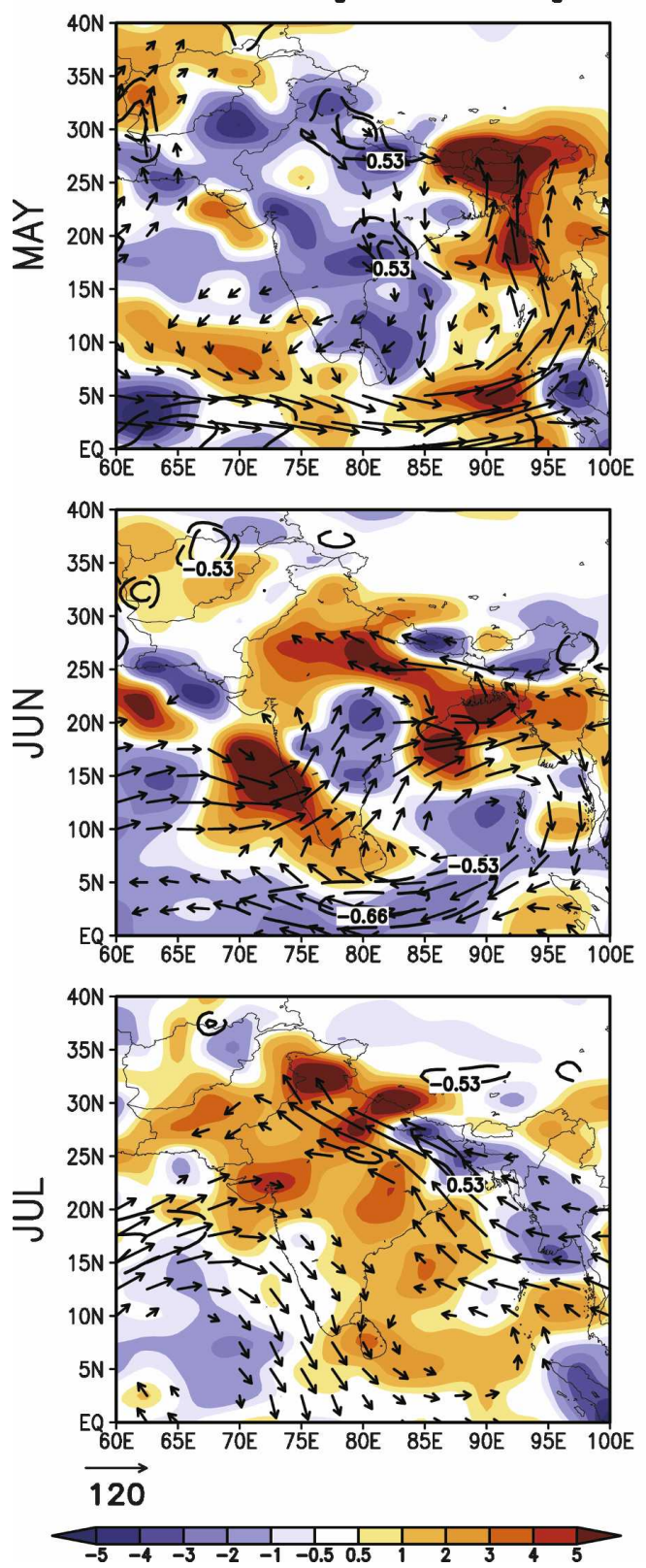

Streaml. and $-0 \mathrm{mega}[75-80 \mathrm{E}]$
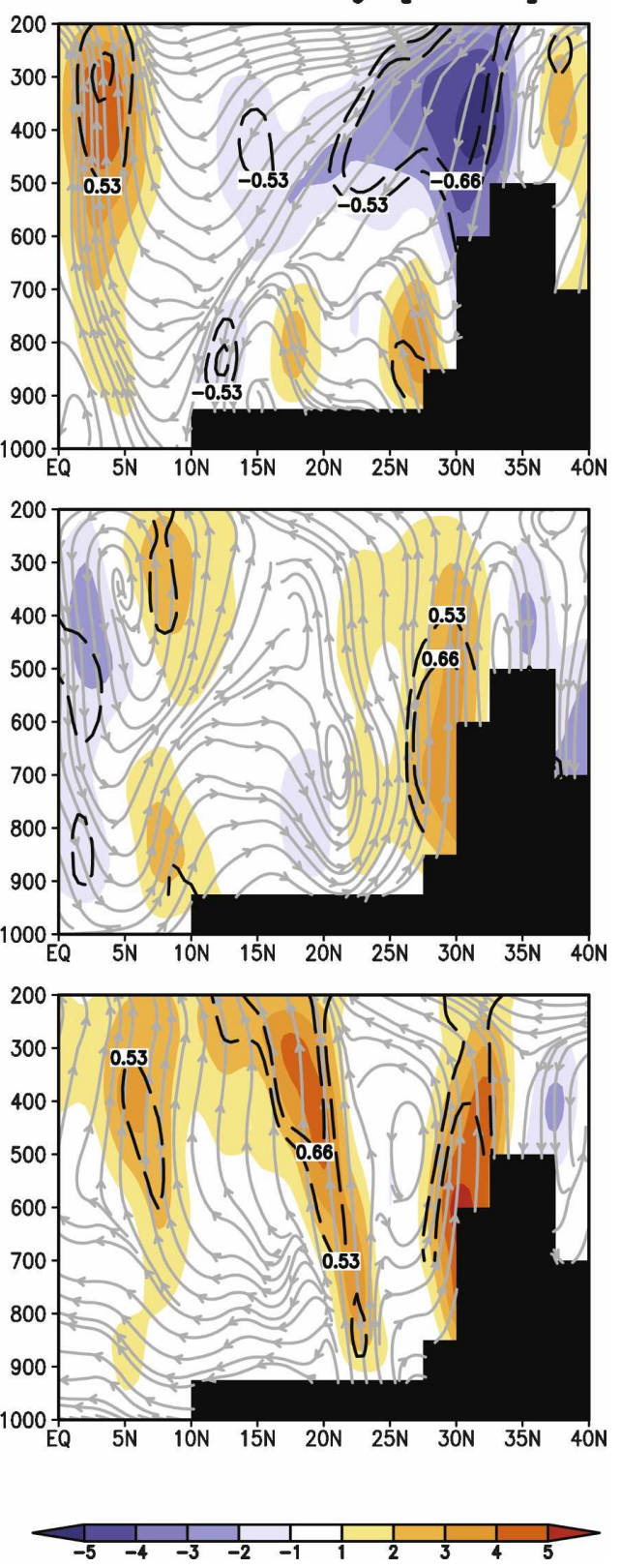

FIG. 6. (left) Moisture flux ( $\mathrm{kg} \mathrm{m}^{-1} \mathrm{~s}^{-1}$; vector values below $20 \mathrm{~kg} \mathrm{~m}^{-1} \mathrm{~s}^{-1}$ have been masked out) and its convergence $\left(\mathrm{kg} \mathrm{m}^{-2} \mathrm{~s}^{-1}\right.$; shaded, positive values representing convergence) mass-weighted vertically integrated between 1000 and $500 \mathrm{hPa}$ and regressed on the AI time series (see Fig. 1) for (top to bottom) May, June, and July. (right) Latitude-height cross section (average between $75^{\circ}-80^{\circ} \mathrm{E}$; topography in black) of streamlines (continuous gray lines) and $\omega$ (shaded; in $10^{2} \mathrm{~Pa} \mathrm{~s}^{-1}$ ) regressed on the AI time series for (top to bottom) May, June, and July. The \pm 0.53 and \pm 0.66 dashed lines show the $95 \%$ and $99 \%$ confidence levels, respectively, for the moisture flux and vertical velocity.

cipitation (cf. Fig. 3). Cooler temperatures, on the other hand, are evident over eastern India, Bangladesh, and Myanmar (aka Burma) consistent with increased May rainfall over these regions.
Positive sensible heat flux anomalies (i.e., to the atmosphere) are present over India in May, indicating that the lower troposphere is being heated from below, in accord with diabatic heating and temperature distri- 
(a) $\mathrm{T}(\mathrm{K})$ regress. on $\mathrm{Al}$

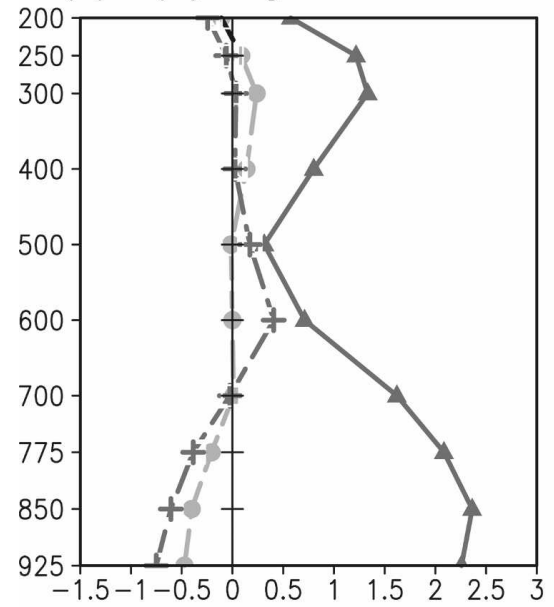

(c) $Q(\mathrm{~g} / \mathrm{kg})$ regress. on $\mathrm{Al}$

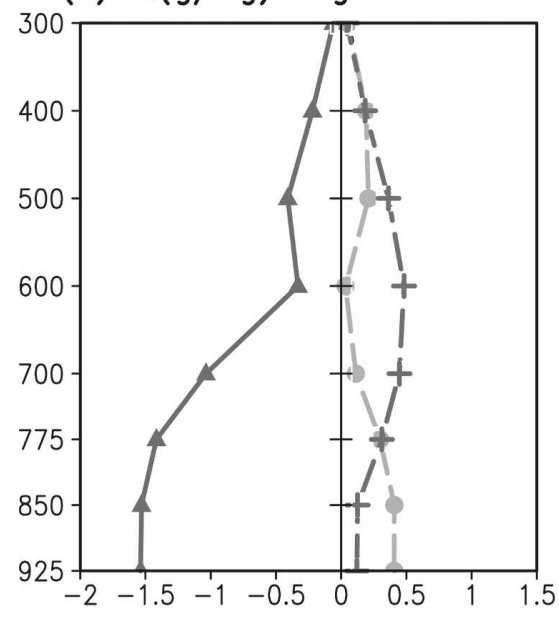

(b) Correlation T - Al

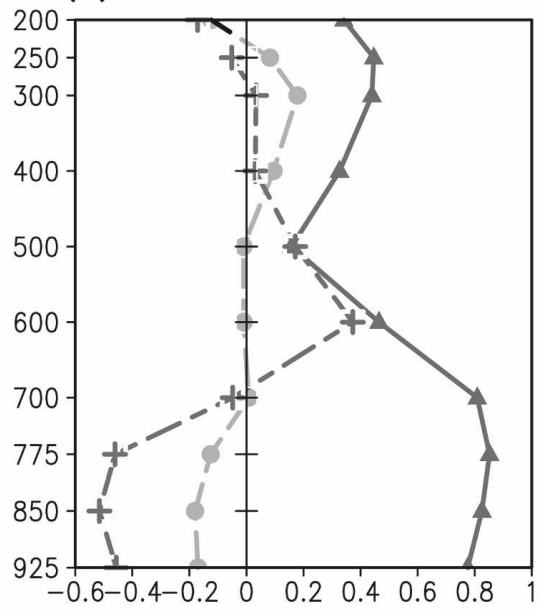

(d) Correlation $\mathrm{Q}-\mathrm{Al}$

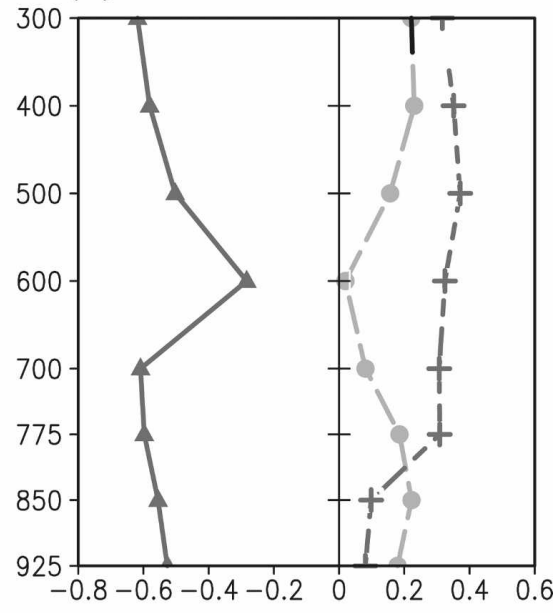

$\longrightarrow$ MAY -- JUN +- JUL

FIG. 7. Vertical profiles (average over $20^{\circ}-25^{\circ} \mathrm{N}, 75^{\circ}-80^{\circ} \mathrm{E}$ ) of (top) temperature (K) and (bottom) specific humidity $\left(\mathrm{g} \mathrm{kg}^{-1}\right)$ regressed on (correlated with) the AI time series (see Fig. 1) for May (solid line with triangle marks), June (dashed line with closed circle marks), and July (dashed line with plus marks). (a), (c) Regressions are shown; (b), (d) correlations are shown.

butions. ${ }^{4}$ At the same time, latent heat flux anomalies are negative, indicating reduced evaporation which must be a consequence of diminished May rainfall. Ex-

\footnotetext{
${ }^{4}$ If all the sensible heat flux $\left(\sim 10 \mathrm{~W} \mathrm{~m}^{-2}\right)$ went into heating the planetary boundary layer (e.g., $2 \mathrm{~km}$ thick), the average temperature tendency would be $\sim 0.45 \mathrm{~K} \mathrm{day}^{-1}\left[=10 /\left(\rho C_{p} 2000\right)\right.$, where $\rho$ is the air density and $C_{p}$ is the specific heat of air]. In the absence of thermal advection and other compensations, a radiative damping time scale of a week would yield a temperature perturbation of $\sim 3 \mathrm{~K}$, an estimate in line with the displayed values of the field (cf. Fig. 6).
}

amination of soil moisture anomalies (not shown) indicates depletion in all soil layers, which is consistent with reduced May evaporation.

The corresponding June anomalies (Fig. 8, right panels) show that land cools down as a result of increased precipitation, inducing a negative sensible heat flux anomaly. The latent heat flux, on the other hand, is nearly neutral because some of the excessive rainfall goes into recharging the drier-than-average land surface. Again, the soil moisture distribution is consistent: slightly positive near-surface anomalies atop negative ones in the two deepest layers (below $28 \mathrm{~cm}$ ). 

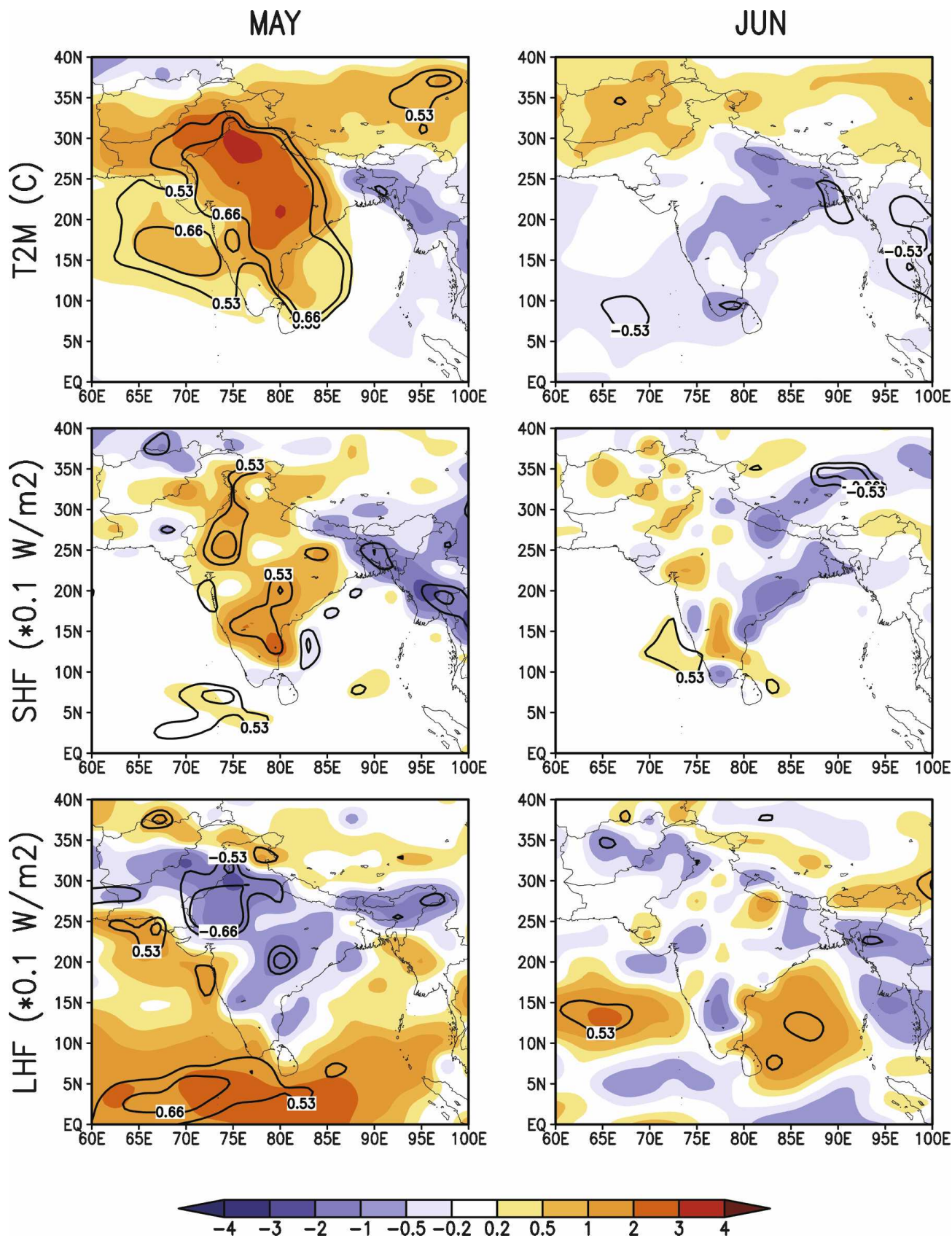

FIG. 8. (top) Air temperature at $2 \mathrm{~m}\left({ }^{\circ} \mathrm{C}\right)$, (middle) sensible heat flux $\left(\mathrm{W} \mathrm{m}^{-2}\right)$, and (bottom) latent heat flux $\left(\mathrm{W} \mathrm{m}^{-2}\right.$ ) regressed on the AI time series (see Fig. 1) for (left) May and (right) June. Positive fluxes are from the surface to the atmosphere. The \pm 0.53 and \pm 0.66 contour lines show the $95 \%$ and $99 \%$ confidence levels, respectively.

The impact of IGP AI variations on downward surface shortwave (SW) radiation is depicted in Fig. 9. A positive anomaly exceeding $20 \mathrm{~W} \mathrm{~m}^{-2}$ is seen over the subcontinent with a core over central India $\left(15^{\circ} \mathrm{N}\right.$, $80^{\circ} \mathrm{E}$ ). The ERA-40 pattern corresponds (with opposite sign) to the precipitation anomaly in the model (cf. Fig. 3 ). Independent observational estimates of the down- ward surface SW flux, also shown in Fig. 9, confirm the above characterization of the SW flux anomaly given the remarkable similarity of the May patterns over both land and ocean. Interestingly, model and observational estimates fall apart in June, especially over the continent and when precipitation is enhanced.

The finding of more downward surface SW radiation 

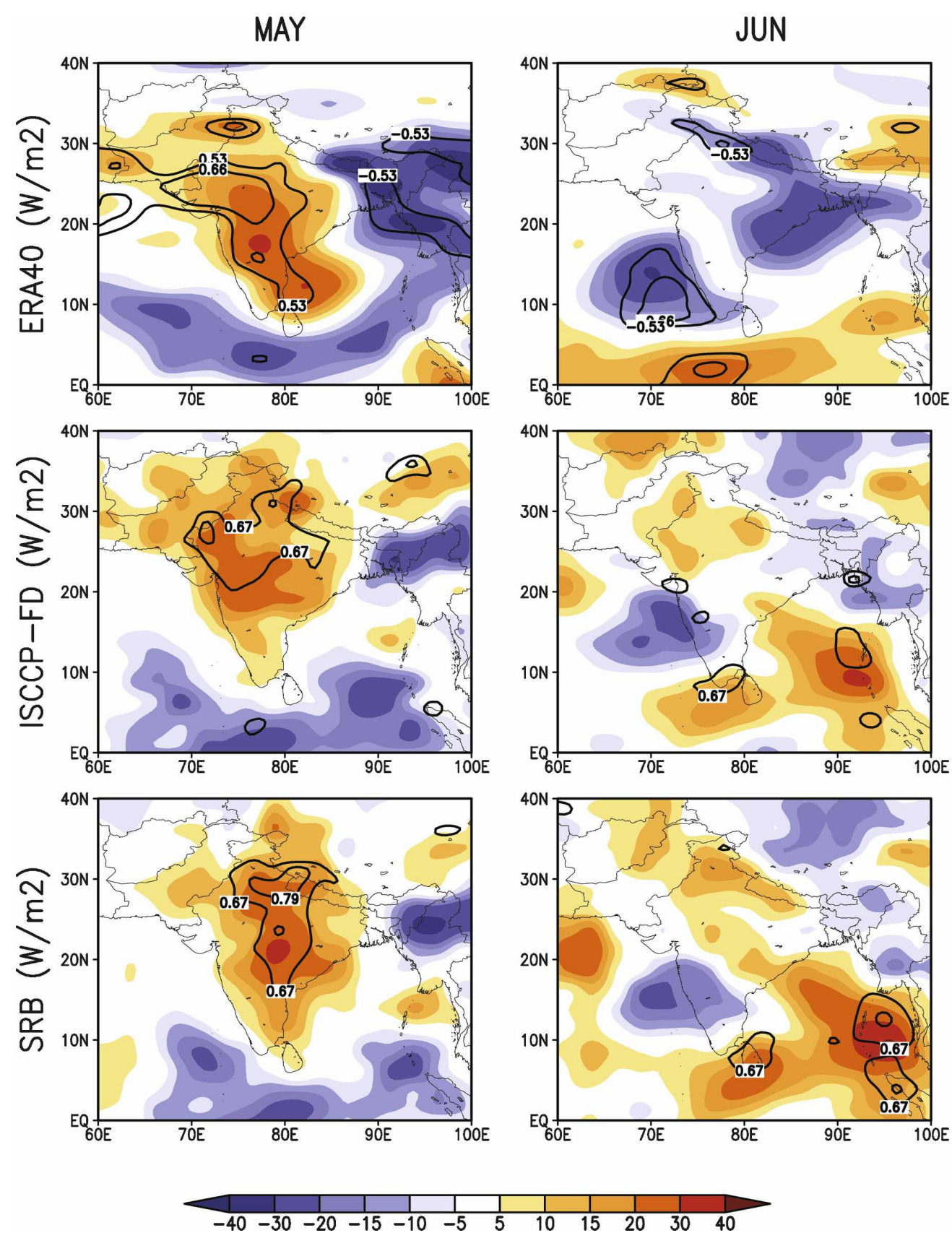

FIG. 9. Downward SW radiation at the surface $\left(\mathrm{W} \mathrm{m}^{-2}\right)$ regressed on the AI time series (see Fig. 1) for (left) May and (right) June based on (top) ERA-40, (middle) ISCCP-FD, and (bottom) GEWEX/SRB. ERA-40 data are for $1979-92$ (the \pm 0.53 and \pm 0.66 contour lines show the $95 \%$ and $99 \%$ confidence levels, respectively) and ISCCP-FD and GEWEX/SRB data cover 1984-92 (the \pm 0.67 and \pm 0.79 contour lines show the $95 \%$ and $99 \%$ confidence levels, respectively).

during periods of increased absorbing-aerosol loadings is at some odds with the winter season analyses. This is in part due to cloudiness variations that are muted in winter, at least, over the IGP region.

The related net longwave (LW) flux anomalies are shown in Fig. 10. The anomalies are strongly positive, exceeding $30 \mathrm{~W} \mathrm{~m}^{-2}$, over the IGP region and northwestern India, especially in the observational estimates. Thus, there is indication of more LW cooling in May, consistent with the warmer underlying land surface and less cloudiness (as shown in the next figure).

Having accumulated indirect evidence for reduced 

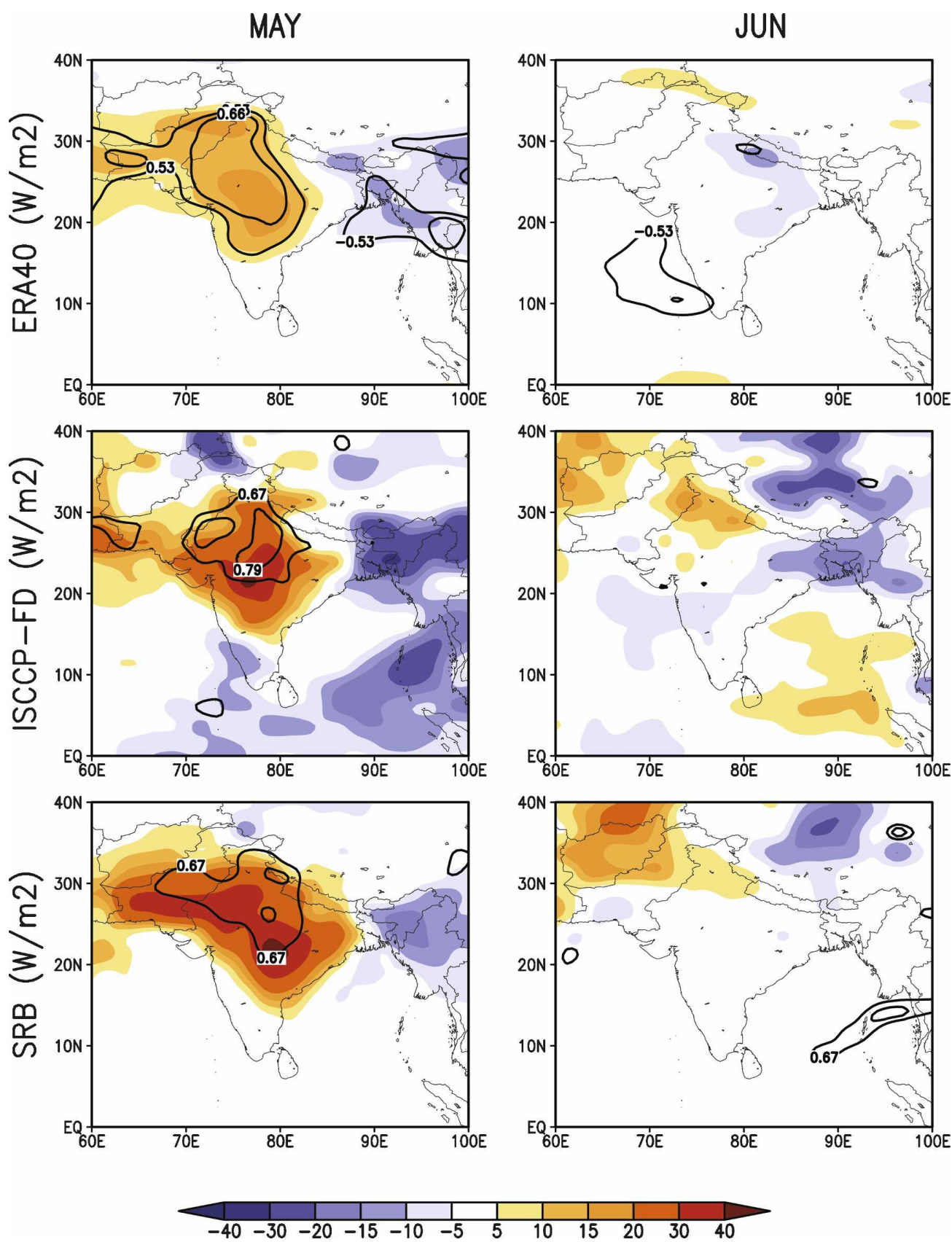

FIG. 10. Same as Fig. 9, but for net LW radiation at the surface (upward flux is positive).

cloudiness in May with increased absorbing aerosol loading over the IGP region (including reduced precipitation, more OLR, more downward SW, increased surface air temperature, and sensible heat flux), the observed low, middle, and high cloud amount anomalies are examined in Fig. 11. Not surprisingly, cloud amount is found significantly reduced at all levels over central and northwestern India in May with the pattern corre- sponding well to the shortwave radiation and precipitation anomaly patterns of that month. The negative anomaly of cloudiness is larger for low and middle clouds, with the highest significance (and spatial extension) in the middle levels. Excess precipitation off the western coast of India and over Bangladesh and eastern India is also consistent with the positive local anomalies of low and middle cloud amount. 

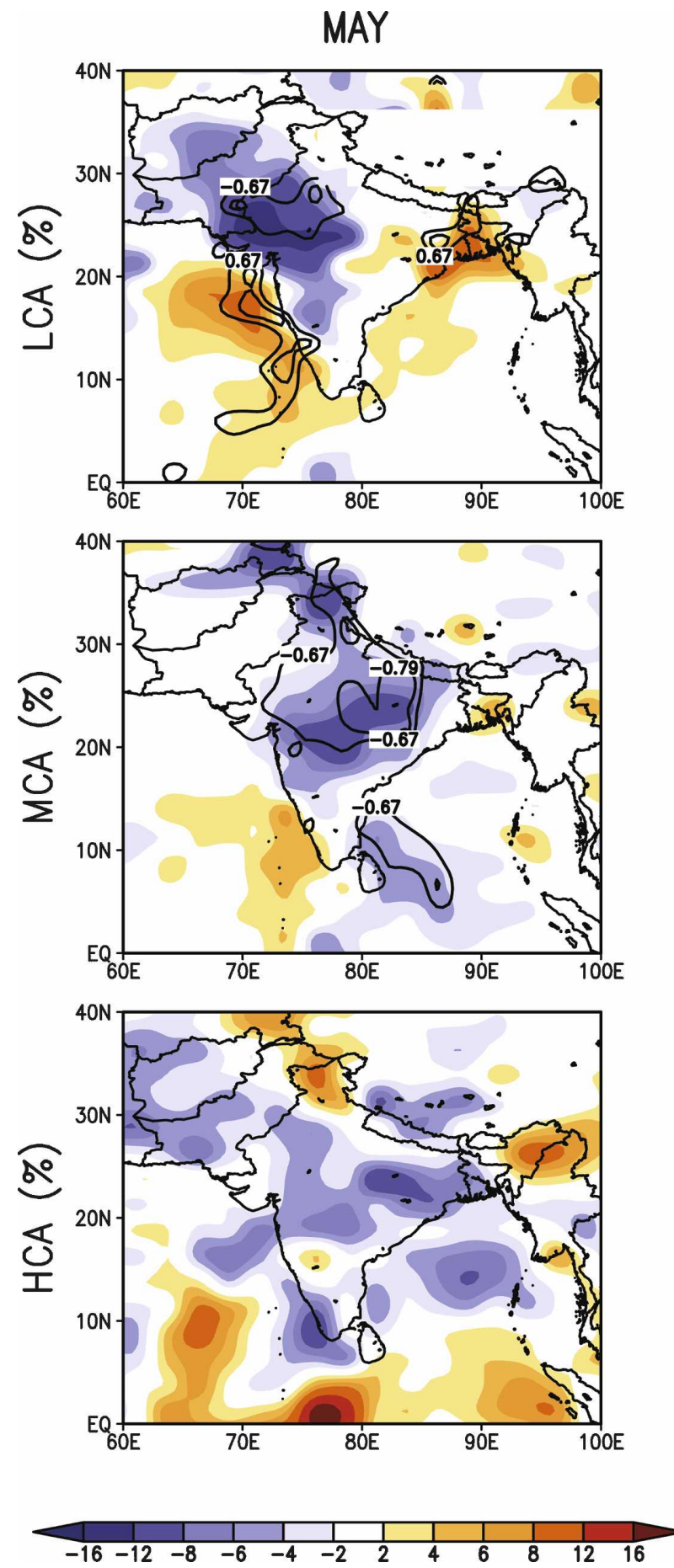

FIG. 11. Low (LCA), middle (MCA), and high (HCA) cloud amount (\%) regressed on the AI time series (see Fig. 1) for (top) May and (bottom) June based on ISCCP-D2. Data are for 198492 , and the \pm 0.67 and \pm 0.79 contour lines show the $95 \%$ and $99 \%$ confidence levels, respectively.

\section{Synopsis and concluding remarks}

The influence of aerosol variability on the South Asian summer monsoon is characterized by means of an observational analysis. Absorbing aerosols have been shown to be influential in the context of long-term changes (or trends) in summer monsoon rainfall (e.g., Ramanathan et al. 2005; Chung and Ramanathan 2006; Lau et al. 2006; Meehl et al. 2008) and its interannual variability (LK06). The summer season is particularly challenging because extensive cloudiness at this time brings the aerosol indirect effects into play in addition to the land and ocean surface-related feedbacks.

The present study focuses on the interannual variability, rather than trend, of absorbing aerosols over South Asia. It provides insight how year-to-year variations of aerosols over the Indo-Gangetic Plain in May impact the subsequent summer monsoon.

Our analysis suggests that the significant large-scale aerosol influence on monsoon circulation and hydroclimate is mediated by heating of the land surface, pursuant to reduced cloudiness and precipitation in May. The finding of the significant role of the land surface in the realization of the aerosol impact is somewhat novel, as best as we can tell, as only the heating of the lower troposphere and solar dimming effects on both land and oceans have hitherto been emphasized, albeit in context of long-term trends. ${ }^{5}$ More specifically, we found the following:

- Excessive aerosol in May leads to reduced cloud amount and precipitation, increased surface shortwave radiation, and land surface warming. The impacts and their relationships are supported by the structure of related vertical motion, diabatic heating, and OLR anomalies. Our analysis suggests that the "aerosol indirect/semi-direct effects" more than offset solar dimming (the direct effect of absorbing aerosol) over the subcontinent, in context of interannual variability.

- The June (and July) monsoon anomaly associated with excessive May aerosols is of opposite sign over much of the subcontinent (although with a different pattern): The monsoon strengthens.

Our analysis suggests the following physical picture: Absorbing aerosols are responsible for a decrease of cloudiness over India in May, which leads, above all, to reduced precipitation, increased shortwave radiation at the surface, and heating of the dry ground. These

\footnotetext{
${ }^{5}$ LK06 argue for the importance of aerosol-induced low-level heating, even in the context of interannual variability.
} 
changes may be attributed to the evaporation of the cloud layer from the absorption of solar radiation by aerosols and subsequent heating of the air-also known as the "semi direct" effect (e.g., Hansen et al. 1997; Ackerman et al. 2000; Kaufman and Koren 2006). Indeed, the resulting decrease in cloud cover and albedo can lead to a warming of the surface, reaching a magnitude that can exceed the cooling from the direct effect (Ackerman et al. 2000).

As the season progresses, the monsoon intensifies and, although we have not conducted a modeling analysis to connect the anomalous heating of the land surface in May to increased monsoon rainfall in June and July over both local and remote regions, we argue that the enhancement of the monsoon results from the increased thermal contrast (originated in May) as in the basic monsoon mechanism.

Our finding on the aerosol-monsoon link in May is based on contemporaneous correlations. As such, one could argue that deficient rainfall in May (from other causes) leads to less aerosol washout, and thus greater aerosol concentration in the same month. This possibility, however, is refuted based on additional correlation analysis (not reported) in which the April AI over the IGP region is correlated with precipitation and circulation anomalies in May and June. The lagged patterns regressed on April AI are found to be similar to the ones described above using the May AI, with the aerosol signal leading the May-June heating and circulation anomalies, indicating causality and support for our hypothesis. Lagged regressions allow such inference only because the IGP aerosol anomalies are reasonably long lived within each season, as indicated by the modest one-month drop in April and May AI autocorrelations (cf. Fig. 1f). Figure 2, moreover, shows that IGP aerosols are fueled up during the premonsoon months not only by local sources but also by the dust advected in by the prevailing westerly low-level flow.

An important analyzed field is diabatic heating, which was residually diagnosed from the ERA-40 reanalysis using the thermodynamic equation. The diagnosed heating should implicitly include the component induced by shortwave radiation absorption to the extent that its influence is manifest in the synoptic scale circulation and temperature fields being assimilated. The residual method, of course, does not yield the partitioned heating components whose knowledge would be helpful in elucidating the mechanisms generating the aerosol effects. Thus, it is entirely possible that the heating induced by absorption of shortwave radiation is obliterated by the much larger latent heating anomalies in summer. The heating field is of great interest as significant low-level heating anomalies in May, with a sur- face trapped structure, provided the first clue to how the low-level atmosphere is being heated.

As mentioned in section 1, the present study has common elements with LK06, who also analyzed the impact of absorbing aerosols in late spring on the summer monsoon evolution. While both analyses show enhancement of the monsoon in June and July subsequent to the enhanced aerosol loading in May, the processes hypothesized as being responsible for this appear to be different. LK06 emphasizes the piling up of aerosols against the southern slopes of the Himalayas and the consequent elevated heating of the atmosphere. Our analysis (e.g., Figs. 3-6) suggests that the aerosol impact and operative processes over central and western India are quite different, if not opposite, to those over the eastern regions. These processes are not well captured by the broad longitudinal sector average $\left(65^{\circ}-95^{\circ} \mathrm{E}\right)$ and the use of bimonthly averages in LK06. In the analysis presented here, there is positive vertical motion and orographic precipitation associated with northward flow against the Himalayas eastward of $\sim 90^{\circ} \mathrm{E}$ in May (see, e.g., Figs. 3 and 6), and although spatially confined this is the region that dominates the zonal averages in Figs. 2 and 3 of LK06, overwhelming the negative anomaly in the larger sector west of $90^{\circ} \mathrm{E}$. Inspection of the May aerosol distribution (Figs. 1a,b), moreover, shows rather low aerosol concentration in the northeastern region, suggesting that the precipitation anomalies there likely arise from the large-scale circulation response of the aerosol effects to the west. As far as Fig. 4 in LK06 is concerned, the present analysis also finds the atmosphere warmer over India but in May only. Indeed, Fig. 7 shows that the vertical profile in May is very different from that in June.

One issue to be investigated in future analysis is the influence of aerosol-induced SST changes in the Indian Ocean on the South Asian monsoon, possibly through modulation of the meridional temperature gradient and moisture supply. As noted in the introduction, modeling studies of Ramanathan et al. (2005), Chung and Ramanathan (2006), and Meehl et al. (2008) found the gradient modulation to be very influential on summer rainfall, trumping the direct effect of the haze-induced heating of the lower troposphere.

The possible remote impact of the absorbing aerosols also deserves attention (e.g., Chung and Ramanathan 2003). A preliminary analysis of regressions over the tropical region shows that higher aerosol loading over India in May is associated with significant (above the 90\% level) negative anomalies in upper-troposphere diabatic heating and precipitation over the eastern and central equatorial Pacific, and positive anomalies over the western Pacific warm pool (resembling a La Niña- 
like response). Both anomalies persist through the season. Some linkage with the ENSO cycle is conceivable since an above-normal Indian monsoon is linked, albeit weakly, with contemporaneous and lagged La Niñalike responses (e.g., Webster et al. 1998; Chung and Nigam 1999).

The time series of May AI also show a significant (above $90 \%$ confidence level) negative correlation with the North Atlantic Oscillation (NAO) (data are available online at http://www.cgd.ucar.edu/cas/jhurrell/ indices.html) when NAO leads by $1-2$ months. This relationship can be qualitatively explained in terms of springtime surface anomalies over Eurasia induced by variations of the NAO (e.g., Dugam et al. 1997).

A deeper understanding of the causal relationships among the processes involved in the aerosol-monsoon interaction will be facilitated by a higher temporal resolution analysis, such as a pentad analysis which is being planned. The robustness of our findings also needs to be ascertained by using longer records of data.

The analysis presented here, despite many limitations, may have an important bearing on the understanding of current and future variations of the monsoon hydrological cycle which, directly or indirectly, affects more than $60 \%$ of the world population.

Acknowledgments. We thank Dr. V. Ramanathan for his comprehensive and constructive review, which helped to improve the clarity of our presentation. We also thank Steven Chan for sharing the ERA-40 heating data in advance of the related publication. This work is partially supported by the Interdisciplinary Investigation Program, NASA Earth Science Division, and by NSF's Climate and Large-Scale Dynamics program.

\section{REFERENCES}

Ackerman, A. S., O. B. Toon, D. E. Stevens, A. J. Heymsfeld, V. Ramanathan, and E. J. Welton, 2000: Reduction of tropical cloudiness by soot. Science, 288, 1042-1047.

Adler, R. F., and Coauthors, 2003: The version-2 Global Precipitation Climatology Project (GPCP) monthly precipitation analysis (1979-present). J. Hydrometeor., 4, 1147-1167.

Anderson, T. L., R. J. Charlson, S. E. Schwartz, R. Knutti, O. Boucher, H. Rodhe, and J. Heintzenberg, 2003: Climate forcing by aerosols-A hazy picture. Science, 300, 1103-1104.

Annamalai, H., K. Hamilton, and K. R. Sperber, 2006: South Asian summer monsoon and its relationship with ENSO in the IPCC AR4 simulations. J. Climate, 20, 1071-1092.

Cakmur, R. V., R. L. Miller, and I. Tegen, 2001: A comparison of seasonal and interannual variability of soil dust aerosols over the Atlantic Ocean as inferred by the TOMS AI and AVHRR AOT retrievals. J. Geophys. Res., 106 (D16), 18 287-18 304.

Chan, S. C., and S. Nigam, 2008: Residual diagnosis of diabatic heating from ERA-40 and NCEP reanalyses: Intercomparisons with TRMM. J. Climate, in press.

Chiapello, I., J. M. Prospero, J. R. Herman, and N. C. Hsu, 1999: Detection of mineral dust over the North Atlantic Ocean and Africa with the Nimbus 7 TOMS. J. Geophys. Res., 104, 92779291.

Chung, C. E., and S. Nigam, 1999: Asian summer monsoonENSO feedback on the Cane-Zebiak model ENSO. J. Climate, 12, 2787-2807.

, and V. Ramanathan, 2003: South Asian haze forcing: Remote impacts with implications to ENSO and AO. J. Climate, 16, 1791-1806.

_ , and _ 2006: Weakening of North Indian SST gradients and the monsoon rainfall in India and the Sahel. J. Climate, 19, 2036-2045.

,-- , and J. T. Kiehl, 2002: Effects of the South Asian absorbing haze on the northeast monsoon and surface-air heat exchange. J. Climate, 15, 2462-2476.

, — - D. Kim, and I. Podgorny, 2005: Global anthropogenic aerosol direct forcing derived from satellite and groundbased observations. J. Geophys. Res., 110, D24207, doi:10.1029/2005JD006356.

Dey, S., S. N. Tripathi, and R. P. Singh, 2004: Influence of dust storms on the aerosol optical properties over the IndoGangetic basin. J. Geophys. Res., 109, D20211, doi:10.1029/ 2004JD004924.

Dugam, S. S., S. B. Kakade, and R. K. Verma, 1997: Interannual and long-term variability in the North Atlantic Oscillation and Indian summer monsoon rainfall. Theor. Appl. Climatol., 58, 21-29.

Duncan, B. N., R. V. Martin, A. C. Staudt, R. Yevich, and J. A. Logan, 2003: Interannual and seasonal variability of biomass burning emissions constrained by satellite observations. $J$. Geophys. Res., 108, 4100, doi:10.1029/2002JD002378.

Eck, T. F., B. N. Holben, O. Dubovik, A. Smirnov, I. Slutsker, J. M. Lobert, and V. Ramanathan, 2001: Column-integrated aerosol optical properties over the Maldives during the northeast monsoon for 1998-2000. J. Geophys. Res., 106, $28555-28566$.

Gautam, R., N. C. Hsu, M. Kafatos, and S.-C. Tsay, 2007: Influences of winter haze on fog/low cloud over the Indo-Gangetic plains. J. Geophys. Res., 112, D05207, doi:10.1029/ 2005JD007036.

Gupta, S. K., N. A. Ritchey, A. C. Wilber, C. H. Whitlock, G. G. Gibson, and P. W. Stackhouse Jr., 1999: A climatology of surface radiation budget derived from satellite data. J. Climate, 12, 2691-2710.

Habib, G., C. Venkataraman, I. Chiapello, S. Ramachandran, O. Boucher, and M. S. Reddy, 2006: Seasonal and interannual variability in absorbing aerosols over India derived from TOMS: Relationship to regional meteorology and emissions. Atmos. Environ., 40, 1909-1921.

Hansen, J., M. Sato, and R. Ruedy, 1997: Radiative forcing and climate response. J. Geophys. Res., 102, 6831-6864.

Herman, J. R., P. B. Bhartia, O. Torres, C. Hsu, C. J. Seftor, and E. Celarier, 1997: Global distribution of UV-absorbing aerosols from Nimbus 7/TOMS data. J. Geophys. Res., 102, $16911-16921$.

Hoskins, B. J., H. H. Hsu, I. N. James, M. Masutani, P. D. Sardeshmukh, and G. H. White, 1989: Diagnostics of the global atmospheric circulation based on ECMWF analyses 1979-1989. WCRP-27, WMO Tech. Doc. 326, 217 pp.

Hsu, N. C., and Coauthors, 1999: Comparisons of the TOMS aero- 
sol index with Sun-photometer aerosol optical thickness: Results and applications. J. Geophys. Res., 104 (D6), 6269-6280.

— J. R. Herman, and S. C. Tsay, 2003: Radiative impacts from biomass burning in the presence of clouds during boreal spring in southeast Asia. Geophys. Res. Lett., 30, 1224, doi:10.1029/2002GL016485.

IPCC, 2007: Climate Change 2007: Synthesis Report. Core Writing Team, R. K. Pachauri, and A. Reisinger, Eds., IPCC, 104 pp.

Kaufman, Y. J., and I. Koren, 2006: Smoke and pollution aerosol effect on cloud cover. Science, 313, 655-658.

Kiss, P., I. M. Jánosi, and O. Torres, 2007: Early calibration problems detected in TOMS Earth-Probe aerosol signal. Geophys. Res. Lett., 34, L07803, doi:10.1029/2006GL028108.

Lau, K.-M., and K.-M. Kim, 2006: Observational relationships between aerosol and Asian monsoon rainfall, and circulation. Geophys. Res. Lett., 33, L21810, doi:10.1029/2006GL027546.

- - - a and K.-M. Kim, 2006: Asian summer monsoon anomalies induced by aerosol direct forcing: The role of the Tibetan Plateau. Climate Dyn., 26, 855-864.

Lelieveld, J., and Coauthors, 2001: The Indian Ocean experiment: Widespread air pollution from South and Southeast Asia. Science, 291, 1031-1036.

Liebmann, B., and D. L. Hartmann, 1982: Interannual variations of outgoing IR associated with tropical circulation changes during 1974-78. J. Atmos. Sci., 39, 1153-1162.

— lated) outgoing longwave radiation dataset. Bull. Amer. Meteor. Soc., 77, 1275-1277.

Massie, S. T., O. Torres, and S. J. Smith, 2004: Total Ozone Mapping Spectrometer (TOMS) observations of increases in Asian aerosol in winter from 1979 to 2000. J. Geophys. Res., 109, D18211, doi:10.1029/2004JD004620.

Meehl, G. A., J. M. Arblaster, and W. D. Collins, 2008: Effects of black carbon aerosols on the Indian monsoon. J. Climate, 21, 2869-2882.

Menon, S., 2004: Current uncertainties in assessing aerosol effects on climate. Annu. Rev. Environ. Resour., 29, 1-30.

_ J. Jansen, L. Nazarenko, and Y. Luo, 2002: Climate effects of black carbon aerosols in China and India. Science, 297, 2250-2253.

Mitchell, T. D., and P. D. Jones, 2005: An improved method of constructing a database of monthly climate observations and associated high-resolution grids. Int. J. Climatol., 25, 693-712.

New, M., M. Hulme, and P. Jones, 2000: Representing twentiethcentury space-time climate variability. Part II: Development of 1901-96 monthly grids of terrestrial surface climate. J. Climate, 13, 2217-2238.

Nigam, S., 1994: On the dynamical basis for the Asian summer monsoon rainfall-El Niño relationship. J. Climate, 7, 17501771.

Prospero, J. M., P. Ginoux, O. Torres, S. E. Nicholson, and T. E. Gill, 2002: Environmental characterization of global sources of atmospheric soil dust identified with the Nimbus 7 Total Ozone Mapping Spectrometer (TOMS) absorbing aerosol product. Rev. Geophys., 40, 1002, doi:10.1029/ 2000RG000095.

Rajeev, K., and V. Ramanathan, 2002: The Indian Ocean experiment: Aerosol forcing obtained from satellite data. $A d v$. Space Res., 29, 1731-1740.

$\longrightarrow,-$, and J. Meywerk, 2000: Regional aerosol distribution and its long-range transport over the Indian Ocean. J. Geophys. Res., 105 (D2), 2029-2044.

Ramana, M. V., V. Ramanathan, I. A. Podgorny, B. B. Pradhan, and B. Shrestha, 2004: The direct observations of large aerosol radiative forcing in the Himalayan region. Geophys. Res. Lett., 31, L05111, doi:10.1029/2003GL018824.

Ramanathan, V., and M. V. Ramana, 2005: Persistent, widespread, and strongly absorbing haze over the Himalayan foothills and the Indo-Gangetic Plains. Pure Appl. Geophys., 162, 1609-1626.

- , and Coauthors, 2001: Indian Ocean experiment: An integrated analysis of the climate forcing and effects of the great Indo-Asian haze. J. Geophys. Res., 106 (D22), 28 371-28 398. , and Coauthors, 2005: Atmospheric brown clouds: Impacts on South Asian climate and hydrological cycle. Proc. Natl. Acad. Sci. USA, 102, 5326-5333.

Rossow, W. B., A. W. Walker, D. E. Beuschel, and M. D. Roiter, 1996: International Satellite Cloud Climatology Project (ISCCP) documentation of new cloud datasets. WMO Tech. Doc. 737, 115 pp.

Sarkar, S., R. Chokngamwong, G. Cervone, R. P. Singh, and M. Kafatos, 2006: Variability of aerosol optical depth and aerosol forcing over India. Adv. Space Res., 37, 2153-2159.

Torres, O., P. K. Bhartia, J. R. Herman, Z. Ahmad, and J. Gleason, 1998: Derivation of aerosol properties from satellite measurements of backscattered ultraviolet radiation: Theoretical basis. J. Geophys. Res., 103, 17 099-17 110.

,,,--- A. Sinyuk, P. Ginoux, and B. Holben, 2002: A long-term record of aerosol optical depth from TOMS observations and comparison to AERONET measurements. $J$. Atmos. Sci., 59, 398-413.

Uppala, S. M., and Coauthors, 2005: The ERA-40 Re-Analysis. Quart. J. Roy. Meteor. Soc., 131, 2961-3012.

Webster, P. J., V. O. Magana, T. N. Palmer, J. Shukla, R. A. Tomas, M. Yanai, and T. Yasunari, 1998: Monsoons: Processes, predictability, and the prospects for prediction. J. Geophys. Res., 103, 14 451-14 510.

Xie, P., and P. A. Arkin, 1997: Global precipitation: A 17-year monthly analysis based on gauge observations, satellite estimates, and numerical model outputs. Bull. Amer. Meteor. Soc., 78, 2539-2558.

Zhang, Y., W. B. Rossow, A. A. Lacis, V. Oinas, and M. I. Mishchenko, 2004: Calculation of radiative fluxes from the surface to top of atmosphere based on ISCCP and other global data sets: Refinements of the radiative transfer model and the input data. J. Geophys. Res., 109, D19105, doi:10.1029/ 2003JD004457. 